\title{
Absidia corymbifera endocarditis: Survival after treatment of disseminated mucormycosis with radical resection of tricuspid valve and right ventricular free wall
}

\author{
Michael E. Mitchell, MD, ${ }^{\mathrm{a}}$ Michael McManus, MD, ${ }^{\mathrm{d}}$ Julie Dietz, MD, ${ }^{\mathrm{d}}$ Bruce M. Camitta, MD, \\ Sara Szabo, MD, PhD, ${ }^{\mathrm{c}}$ and Peter Havens, MD, ${ }^{\mathrm{b}}$ Milwaukee and Marshfield, Wis
}

Disseminated mucormycosis is a rare and almost universally fatal disorder. ${ }^{1,2}$ Successful treatment requires complete surgical resection combined with antifungal chemotherapy, but such resection may be impossible when cardiac tissues are involved. ${ }^{3}$ There are few reports of successfully treated mucormycosis in cardiac tissues and no reports of successfully treated native valve endocarditis caused by mucormycosis or zygomycosis. ${ }^{4-11}$ We describe the cure of disseminated mucormycosis and native tricuspid valve endocarditis in a 6year-old child to demonstrate the possibility of a successful outcome and emphasize the need for aggressive resection.

\section{CLINICAL SUMMARY}

The patient was a 6-year-old previously healthy girl in whom T-cell acute lymphoblastic leukemia was diagnosed. She underwent four drug induction treatments lasting 28 days according to Children's Oncology Group regimen AALL0232 PC. This regimen included vincristine, prednisone, daunorubicin, and pegaspargase, plus intrathecal treatment with cytarabine and methotrexate. The disease was in complete remission at the end of induction, and she began consolidation therapy that included cyclophosphamide, cytarabine, mercaptopurine, vincristine, and pegaspargase, plus intrathecal methotrexate. On day 40 of consolidation therapy, the patient was readmitted for fever to $104.3^{\circ} \mathrm{F}$ $\left(40^{\circ} \mathrm{C}\right)$, neutropenia, and tachycardia. On hospital day 3, central venous line blood culture showed growth of filamentous fungus (later identified as Absidia corymbifera). Amphotericin B (Ambisome, $5 \mathrm{mg} / \mathrm{kg}$ per dose) was started, and the central venous line was removed. Computed tomographic scan of the neck, chest, abdomen, and pelvis showed bilateral nodular pulmonary densities and a right ventricular mass. Echocardiogram defined a $2 \times 1.5$-cm right ventricular mass without outflow tract obstruction.

\footnotetext{
From the Departments of Surgery, ${ }^{\mathrm{a}}$ Pediatrics, ${ }^{\mathrm{b}}$ and Pathology, ${ }^{\mathrm{c}}$ Medical College of Wisconsin, Children's Hospital of Wisconsin, Milwaukee, Wis; and the Department of Pediatrics, ${ }^{\mathrm{d}}$ Marshfield Clinic/Saint Joseph's Hospital, Marshfield, Wis. Disclosures: None.

Received for publication May 15, 2008; accepted for publication July 3, 2008

Address for reprints: Michael E. Mitchell, Department of Surgery, Children's Hospital of Wisconsin, Medical College of Wisconsin, 9000 W Wisconsin Ave, MS 715,

Milwaukee, WI 53226 (E-mail: MMitchell@chw.org).

J Thorac Cardiovasc Surg 2010;139:e71-2

$0022-5223 / \$ 36.00$

Copyright $₫ 2010$ by The American Association for Thoracic Surgery

doi: $10.1016 / j$.jtcvs.2008.07.073
}

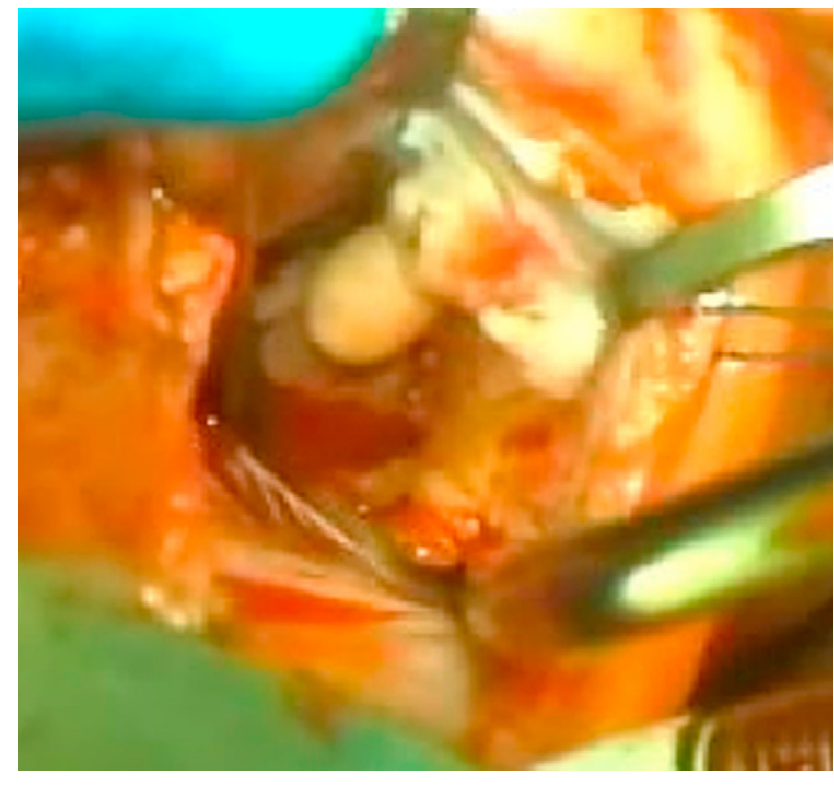

FIGURE 1. Intraoperative photograph immediately before radical resection.

The patient was taken to the operating room on an emergency basis. Surgery consisted of débridement of a large (3 $\times 3 \mathrm{~cm}$ ) fungus ball inferior to the posterior leaflet of the tricuspid valve and involving the free wall of the right ventricle. The resection was not complete. The posterior leaflet of the tricuspid valve and subvalvular apparatus were intimately involved with a small amount of grossly detectable fungus. Lung lesions were not resected. Amphotericin B was increased to $10 \mathrm{mg} / \mathrm{kg}$ per day. The patient recovered rapidly, with no tricuspid insufficiency, and was discharged to home on postoperative day 11 .

On postoperative day 25 , the patient returned to the emergency department with shortness of breath and tachycardia. Spiral chest computed tomography revealed progression of disease, with growth of the mass in the right ventricle and embolization into the right pulmonary artery. She was taken to the operating room on an urgent basis for radical resection of all involved cardiac tissues (Figure 1). This surgery included wide resection of the right ventricular free wall, resection of the posterior leaflet of the tricuspid valve and subvalvular apparatus, and resection of two dominant leftsided lung nodules. All margins were grossly free of fungus. The right ventricle was reconstructed primarily, and the tricuspid valve was bicuspidized with resection of the posterior 


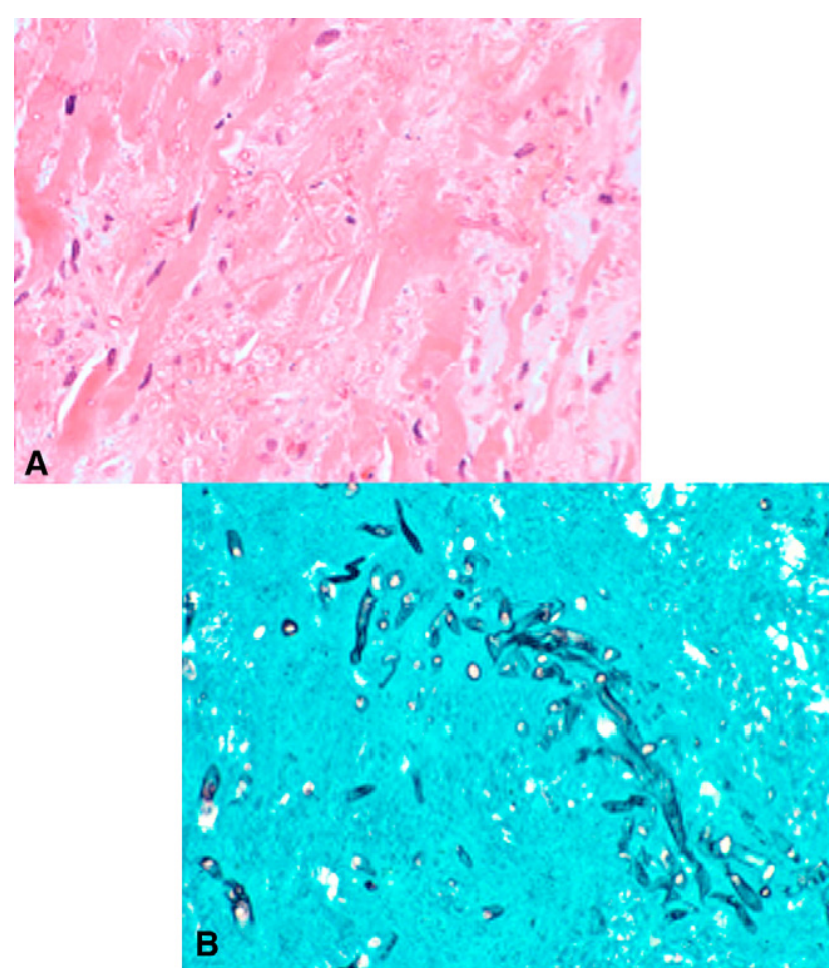

FIGURE 2. Histology. A, Numerous fungal hyphae infiltrating the myocardium, with necrosis (hematoxylin and eosin stain). B, Fungal hyphae morphologically consistant with zygomycetes (Giemsa stain).

leaflet and subvalvular apparatus, followed by an extensive DeVega annuloplasty. Areas of abscess in the left upper lobe and lingula were also removed. Postoperative transesophageal echocardiography confirmed mild to moderate tricuspid regurgitation and mild tricuspid stenosis. The patient was extubated in the operating room and transferred to the intensive care unit with a regimen of dopamine and milrinone, as well as amphotericin $\mathrm{B}(10 \mathrm{mg} / \mathrm{kg}$ per day). Posaconazole (200 mg orally twice daily) was added (under a compassionate use protocol before approval by the Food and Drug Administration). Pathologic examination of the myocardial tissue demonstrated extensively infiltrating fungal hyphae consistent with mucormycosis (zygomycosis), with myocardial necrosis and limited host response (Figure 2). The pulmonary tissue showed only an inflammatory and reparative host reaction. The patient was discharged from the hospital on postoperative day 11 with a regimen of amphotericin B and posaconazole.

Latest echocardiogram at 16 months of follow-up revealed moderate to severe tricuspid regurgitation with good right ventricular function. Now at 21 months after resection, full remission of acute lymphoblastic leukemia continues, and the patient is in New York Heart Association functional class I.

\section{DISCUSSION}

Mucormycosis endocarditis is a rare disorder, typically involving infection of prosthetic valves after cardiac surgery in immunocompromised hosts. ${ }^{5,6,8,9}$ Mucormycosis endocarditis involving a native valve is extremely uncommon. ${ }^{4,10}$ The successful outcome in our case after radical resection of the primary infectious focus, despite disseminated disease with rapidly positive blood cultures, illustrates both the importance of aggressive therapy when possible and the possibility of resolution once the initial focus of infection has been removed. Although the principle of obtaining clear margins in surgical resections of nonessential tissue infected with fungi of the Mucorales order is widely accepted, aggressive resection of essential tissue, such as cardiac tissue, in the face of disseminated disease is not a common practice. In this case radical resection, including bicuspidization of the tricuspid valve, was well tolerated and resulted in clearing of the systemic fungemia, allowing immunosuppressive chemotherapy to be resumed.

Antifungal therapy for mucormycosis with liposomal amphotericin B (Ambisome or Abelcet) may be more effective than therapy with amphotericin B deoxycholate. ${ }^{1}$ Posaconazole may be effective in patients with refractory disease or intolerance of Ambisome therapy. ${ }^{12}$

\section{References}

1. Gleissner B, Schilling A, Anagnostopolous I, Siehl I, Thiel E. Improved outcome of zygomycosis in patients with hematological diseases? Leuk Lymphoma. 2004; 45:1351-60.

2. Spellberg B, Edwards J Jr, Ibrahim A. Novel perspectives on mucormycosis: pathophysiology, presentation, and management. Clin Microbiol Rev. 2005;18: 556-69.

3. Reid VJ, Solnik DL, Daskalakis T, Sheka KP. Management of bronchovascular mucormycosis in a diabetic: a surgical success. Ann Thorac Surg. 2004;78: 1449-51.

4. Chen L, Xiao Y, Wang X. Successful treatment of mucormycosis in the pulmonary artery after cardiac surgery. J Card Surg. 2005;20:186-8.

5. Mehta NN, Romanelli J, Sutton MG. Native aortic valve vegetative endocarditis with. Cunninghamella. Eur J Echocardiogr. 2004;5:156-8.

6. Zhang R, Zhang JW, Szerlip HM. Endocarditis and hemorrhagic stroke caused by Cunninghamella bertholletiae infection after kidney transplantation. Am J Kidney Dis. 2002;40:842-6.

7. Solano T, Atkins B, Tambosis E, Mann S, Gottlieb T. Disseminated mucormycosis due to Saksenaea vasiformis in an immunocompetent adult. Clin Infect Dis. 2000;30:942-3.

8. Sanchez-Recalde A, Merino JL, Dominguez F, Mate I, Larrea JL, Sobrino JA. Successful treatment of prosthetic aortic valve mucormycosis. Chest. 1999; 116:1818-20

9. Mishra B, Mandal A, Kumar N. Mycotic prosthetic-valve endocarditis. J Hosp Infect. 1992;20:122-5.

10. Roy TM, Anderson KC, Farrow JR. Cardiac mucormycosis complicating diabetes mellitus. J Diabet Complications. 1990;4:132-5.

11. Buchbinder NA, Roberts WC. Active infective endocarditis confined to mural endocardium. A study of six necropsy patients. Arch Pathol. 1972;93:435-40.

12. van Burik JA, Hare RS, Solomon HF, Corrado ML, Kontoyiannis DP. Posaconazole is effective as salvage therapy in zygomycosis: a retrospective summary of 91 cases [published erratum appears in Clin Infect Dis] 2006;43:1376]. Clin Infect Dis. 2006;42:e61-5. 